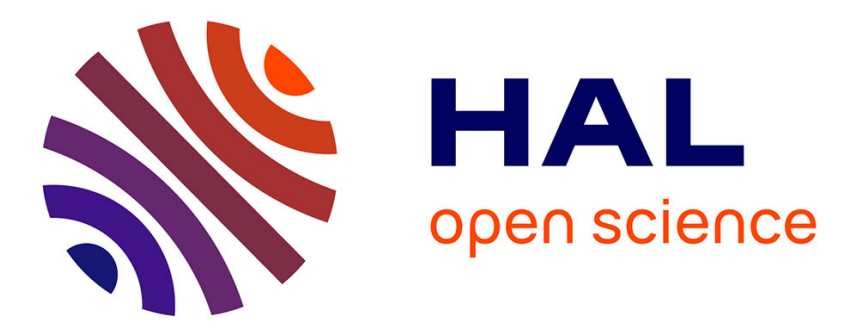

\title{
Chemical effects in ion beam mixing of Fe-Al multilayers
} R. Brenier, B. Canut, L. Gea, S. Ramos, P. Thevenard, C. Dubois, J. Dupuy, G. Prudon, M. Brunel

\section{To cite this version:}

R. Brenier, B. Canut, L. Gea, S. Ramos, P. Thevenard, et al.. Chemical effects in ion beam mixing of Fe-Al multilayers. Journal de Physique IV Proceedings, 1994, 04 (C3), pp.C3-263-C3-271. 10.1051/jp4:1994336 . jpa-00252533

\section{HAL Id: jpa-00252533 https://hal.science/jpa-00252533}

Submitted on 1 Jan 1994

HAL is a multi-disciplinary open access archive for the deposit and dissemination of scientific research documents, whether they are published or not. The documents may come from teaching and research institutions in France or abroad, or from public or private research centers.
L'archive ouverte pluridisciplinaire HAL, est destinée au dépôt et à la diffusion de documents scientifiques de niveau recherche, publiés ou non, émanant des établissements d'enseignement et de recherche français ou étrangers, des laboratoires publics ou privés. 


\title{
Chemical effects in ion beam mixing of Fe-Al multilayers
}

\author{
R. BRENIER, B. CANUT, L. GEA, S.M.M. RAMOS, P. THEVENARD, C. DUBOIS*, \\ J.C. DUPUY* ${ }^{*}$ G. PRUDON ${ }^{*}$ and M. BRUNEL ${ }^{* *}$
}

Université Claude Bernard Lyon I, Département de Physique des Matériaux, URA 172 du CNRS, 69622 Villeurbanne cedex, France

* Laboratoire de Physique de la Matière, I.N.S.A., 20 Avenue Albert Einstein, 69621 Villeurbanne cedex, France

** Laboratoire de Cristallographie, C.N.R.S., 25 Avenue des Martyrs, BP. 166 X, 38042 Grenoble cedex, France

\section{ABSTRACT}

Fe-Al multilayers have been mixed with $\mathrm{Xe}^{+}$ions at high temperatures. The composition depth profiles have been analyzed by secondary ion mass spectroscopy (SIMS). It is shown that SIMS reveals the Al-rich compound formation inside the initial $\mathrm{Al}$ layers, and that this point cannot be questioned by exaltation effect on $\mathrm{Fe}^{+}$or $\mathrm{Al}^{+}$ion intensities. Phase formation has been proved by $\mathrm{X}$-ray diffraction at grazing incidence.

\section{Introduction}

The mechanisms of ion beam mixing (IBM) have widely been investigated since 10 years (1). Three contributions are believed to induce the redistribution of the target atoms : binary collisions, dense cascade collisions sometimes considered as thermal spikes, and radiation enhanced diffusion (RED). RED is efficient if the temperature is not too low ( $\mathrm{T} \geq 300 \mathrm{~K}$ ) and is guided by chemical potential gradients. At low temperature, binary collisions well describe the interaction of light ions with matter whereas thermal spike models are more suitable to reproduce the effects of heavy ions crossing a target of heavy atoms $(Z \simeq 60)$. In this last case it has been shown that the thermodynamic properties of the target such as the cohesive energie $\Delta \mathrm{E}_{\mathrm{c}}$ and the mixing enthalpy $\Delta \mathrm{H}_{\mathrm{m}}$ can greatly influence the mixing process (2) (3). Nevertheless when the atomic number of the target atoms is lower $(Z \sim 30-40)$ the correlation between the mixing efficiency and the thermodynamic parameters is less accurate (4). Moreover for some low- $Z$ metals $(Z \sim 20)$ the correlation is quite questionable (5). The Fe-Al system belongs to this last category and the previous measurements of the mixing efficiency show some dispersion confirming that it is a borderline case $(6,7,8)$.

In this context we have undertaken experiments to try to get evidence of chemical effects in IBM of $\mathrm{Fe}-\mathrm{Al}$ multilayers $(\mathrm{Z} \simeq 20)$ at different temperatures. The preliminary results presented here concerns mixing at temperatures higher than $300 \mathrm{~K}$ since chemical effects via RED undoubtedly exist.

Then our purpose is to test a promising but difficult method : analyzing the composition profile in irradiated Fe-Al multilayers by secondary ion mass spectroscopy (SIMS). Indeed SIMS has the advantage of high sensibility and depth resolution (9) but the drawback of matrix effects (10). Then the relation composition-ion intensities depth profiles has to be well understood. Our experiments consist in mixing Fe$\mathrm{Al}$ multilayer of $\mathrm{Al}$ rich global composition able to lead to metastable phases such quasi-crystals (11 - 12). The $\mathrm{Fe}^{+}$and $\mathrm{Al}^{+}$ion intensity depth profile measured by SIMS are fitted using empirical exaltation coefficients and correlated to the phase formation studied by X-ray diffraction at grazing incidence. 


\section{Experiments}

Multilayers composed of $3 \mathrm{Fe}$ layers alternated with $3 \mathrm{Al}$ layers were deposited by electron-gun evaporation onto optically polished sapphire substrate, in an oil-free vacuum system (10-8 torr). The top layer was of $\mathrm{Al}$ type. The film thicknesses were controlled in situ by a quartz micro-balance.

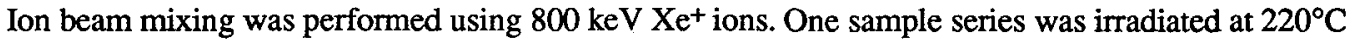
temperature at a fluence of $0.8 \times 10^{16} \mathrm{Xe}^{+} / \mathrm{cm}^{2}$ and a second one was irradiated at $370^{\circ} \mathrm{C}$ at a fluence of $1.5 \times 10^{16} \mathrm{Xe}^{+} / \mathrm{cm}^{2}$.

The elemental composition and the layers thicknesses were measured by Rutherford backscattering spectrometry of $2 \mathrm{MeV}$ alpha particles. The composition profiles were analyzed by SIMS using $\mathrm{O}_{2}{ }^{+}$ions under an oxygen flooding at a saturation pressure of $10^{-5}$ torr. The phases present in the samples before and after mixing were identified by $\mathrm{X}$-ray diffraction at grazing incidence of $0.5^{\circ}$, using $\mathrm{Cu}$ - $\mathrm{K} \alpha$ radiation $(\lambda=0.154 \mathrm{~nm})$.

\section{Results}

\section{- As-deposited multilayers}

The RBS spectrum of the as-deposited sample is shown in figure 1.a. From this spectrum the thickness of each Al layer can be evaluated to $35 \mathrm{~nm}$. The $1^{\text {st }}$ Fe layer has a thickness of $4 \mathrm{~nm}$, and the 2 others, $5 \mathrm{~nm}$. Moreover a pollution of the sample by a small amount of $\mathrm{Cu}$ is appearent. Therefore the global composition of the multilayers is $\mathrm{Al}_{83} \mathrm{Fe}_{16} \mathrm{Cu}_{1}$.

In SIMS analysis (figure 2.a.) the ${ }^{56} \mathrm{Fe}^{+}$and ${ }^{27} \mathrm{Al}^{+}$intensities show all the individual layers. Indeed the depth resolution is about $7 \mathrm{~nm}$ (1). The phase identification is deduced from the $\mathrm{X}$-ray diffraction pattern given in figure 3.a.. Fcc - $\mathrm{Al}$ and bcc - Fe are the only phases present in the sample. All layers are textured since some intense peaks are absent of the spectrum.

\section{- Irradiated multilayers}

After mixing at $220^{\circ} \mathrm{C}$ or $370^{\circ} \mathrm{C}$, the RBS spectra (figure $1 . \mathrm{b}, \mathrm{c}$ ) indicate that interdiffusion has occured in the samples. However only the SIMS technique has a high enough depth resolution to show that the multilayer have not been entirely homogeneized (figure 2. b, c). The total sputtering time in spectra (b) and (c) is shorter than it is in spectrum (a) due to the differences in the primary ion intensity and in the transmittance of the spectrometer. Indeed the multilayer mixed at $220^{\circ} \mathrm{C}$ at the fluence of $0.8 \times 10^{16} \mathrm{Xe}^{+} / \mathrm{cm}^{2}$ presents 8 maxima on the ${ }^{56} \mathrm{Fe}^{+}$signal in phase coïncidence with 8 minima on the $\mathrm{Al}^{+}$signal. The relative amplitude of the modulation of the $\mathrm{Fe}^{+}$intensity is about $50 \%$. The $\mathrm{X}$-ray diffraction pattern is shown in figure 3.b.. Several compounds have been formed : quasi-crystals, $\mathrm{Al}_{5} \mathrm{Fe}_{2}$ and $\mathrm{Al}_{13} \mathrm{Fe}_{4}$. the fcc phase of $\mathrm{Al}$ is still present in the sample.

In the multilayer irradiated at $370^{\circ} \mathrm{C}$ at the fluence of $1.5 \times 10^{16} \mathrm{Xe}^{+} / \mathrm{cm}^{2}$ the $\mathrm{Fe}^{+}$and $\mathrm{Al}^{+}$intensities show the same modulation as for mixing at $220^{\circ} \mathrm{C}$ at the fluence of $0.8 \times 10^{16} \mathrm{Xe}^{+} / \mathrm{cm}^{2}$, with a lower amplitude vanishing close to the substrate. So this last region has a rather flat composition profile $\mathrm{Fe}_{16} \mathrm{Al}_{83}$. $X$-ray diffraction have not yet been performed so the phases formed are still unknown in this sample. 


\section{Discussion and conclusion}

The problem is to explain the surprising number of extrema of $\mathrm{Fe}^{+}$(or $\mathrm{Al}^{+}$) intensity profiles in the SIMS spectra of the mixed samples. The possible role of the main impurities $\mathrm{Cu}, \mathrm{O}$ and $\mathrm{C}$ will first be discussed. The RBS spectra (figure 1) show that the $\mathrm{C}$ and $\mathrm{O}$ contents inside the films are lower than the sensitivity of this technique $(\leq 1$ at. $\%$ ). Indeed this low level due to good vacuum during the metal deposition (10-8 torr) is not expected to have any effect in our results since Gaboriaud et al. (7) have found no difference in mixing measurements of $\mathrm{Fe}$-Al multilayers evaporated in a vacuum of $5 \times 10^{-7}$ or $10^{-9}$ torr. As well the effect of 1 at. \% $\mathrm{Cu}$ on the interdiffusion of the main species $\mathrm{Fe}$ and $\mathrm{Al}$ is likely negligeable. Concerning exaltation effects in SIMS analysis, $\mathrm{Cu}$ and $\mathrm{Fe}$ have similar behavior in $\mathrm{Al}$ alloys (10), so that $\mathrm{Cu}$ is not believed to disturb our SIMS profiles. Then two hypothesis will be examined :

1. The ondulated intensity profile strictly traces the composition profile (no matrix effect in SIMS analysis). Since in the multilayer mixed at $220^{\circ} \mathrm{C}$ at the fluence of $0.8 \times 10^{16} \mathrm{Xe}^{+} / \mathrm{cm}^{2}$ the formation of compounds has been proved by $\mathrm{X}$-ray diffraction, the compounds necessarily form inside the Al layers by Fe diffusion from initial Fe layers. So that an Fe peak ( $\mathrm{N}^{\circ} 1$ in figure 2.b.) is between 2 satellites (1' and 1 " in figure 2.b.). Such a compound precipitation in $\mathrm{Al}$ can be understood since no solid solution of $\mathrm{Fe}$ in $\mathrm{Al}$ exists in the $\mathrm{Al}$ rich side of the equilibrium phase diagram. In a similar way compound precipitation could have occured in the multilayer mixed at $370^{\circ} \mathrm{C}$ at the fluence of $1.5 \times 10^{16} \mathrm{Xe}^{+} / \mathrm{cm}^{2}$. This last point is presently under investigation.

2. The composition profile presents only $3 \mathrm{Fe}$ content maxima centered on the initial Fe layers, the extra maxima being due to matrix effects in SIMS analysis.

In the case where compound formation has been proved, the compounds are supposed to be distributed in the sample so that the Fe content monotonically decrease from initial Fe rich zone to Al rich zone without maxima. Thus we look for a matrix effect responsible for the extra maxima on $\mathrm{Fe}^{+}$intensity profiles.

Matrix effects in SIMS analysis have been investigated by J.L. SERAN, in the Fe-Al system, using $\mathrm{Ar}^{+}$primary ions under an oxygen flooding at saturation pressure (10). These conditions are closed to ours except that $\mathrm{O}_{2}^{+}$ions were used in our case.

The exaltation coefficient of $\mathrm{Fe}^{+}$ions in the $\mathrm{Fe}_{\mathrm{X}} \mathrm{Al}_{1-\mathrm{x}}$ alloy is defined as a function of $\mathrm{x}$ by :

$$
\rho_{\mathrm{Fe}}(\mathrm{x})=\frac{\mathrm{I}_{\mathrm{Fe}}(\mathrm{x})}{\mathrm{x} \mathrm{I}_{\mathrm{Fe}}(\mathrm{x}=1)}
$$

where $\left.\mathrm{IFe}_{\mathrm{Fe}} \mathrm{x}\right)$ is the intensity of $\mathrm{Fe}^{+}$ions sputtered from the $\mathrm{Fe}_{\mathrm{x}} \mathrm{Al}_{1-\mathrm{x}}$ alloy by the $\mathrm{Ar}^{+}$beam.

The measurements of $\rho_{\mathrm{Fe}}(\mathrm{x})$ by SERAN in the range $0.6<\mathrm{x}<1$ have been reported in figure 4.a.. Values for $0<x<0.6$ are "reasonnable" extrapolations supposing that a saturation effect occurs at low $\mathrm{Fe}$ content, as it is the case for the exaltation coefficient of $\mathrm{Cu}$ in $\mathrm{Al}_{\mathrm{X}} \mathrm{Cu}_{1-\mathrm{x}}$ alloys for example (10). Relation [1] allows to calculate $\mathrm{IFe}_{\mathrm{Fe}} \mathrm{x}$ ) for the entire composition range. This has been done in figure 4.b. with $\mathrm{IFe}_{\mathrm{Fe}}$ $=1$ ) $=1$ for simplification.

Let's apply such an exaltation effect to calculate the $\mathrm{Fe}^{+}$intensity depth profile resulting from a given concentration depth profile. In our present hypothesis the interdiffusion between $\mathrm{Fe}$ and $\mathrm{Al}$ initial layers lead to concentration profile rather well represented by a complementary error function. Such a profile is reported in figure 4.c. in the case where $x_{\max }=1$. The exaltation effect induces a shift in the maximum of the 
curve. But such an effect disappears if $x_{\max } \leq 0.6$ (see figure 4.d.) as expected from $\mathrm{IFe}_{\mathrm{Fe}}(\mathrm{x})$ (figure 4.d.).

It is then concluded that matrix effects resulting from exaltation of $\mathrm{Fe}^{+}$intensity in a solid solution $\mathrm{Fe}_{\mathrm{X}} \mathrm{Al}_{1-\mathrm{x}}$ as in SERAN work cannot explain our experimental SIMS spectra, for 2 reasons :

- In the sample mixed at $370^{\circ} \mathrm{C}$ at the fluence of $1.5 \times 10^{16} \mathrm{Xe}^{+} / \mathrm{cm}^{2}$ (figure 2), the concentration profile is closed to the global composition $\mathrm{x}=0.16$, so that matrix effects must be sensitive to Fe content as low as $16 \%$.

- For both mixed samples the $\mathrm{I}_{\mathrm{Fe}}$ profile of an $\mathrm{Fe}$ peak in $\mathrm{Al}$ must contain 3 nearly equal maxima, and not only 2.

Let's try to look for a $\rho_{\mathrm{Fe}}(\mathrm{x})$ function which could qualitatively fit the SIMS spectrum of the multilayer mixed at $370^{\circ} \mathrm{C}$ at the fluence of $1.5 \times 10^{16} \mathrm{Xe}^{+} / \mathrm{cm}^{2}$. If matrix effects are responsible for the slight modulation of $I_{F e}$ the exaltation coefficient $\rho_{F e}(x)$ has to be highly increased near $x=0.16$. Such a coefficient is reported in figure 5.a.. The calculated $\mathrm{Fe}^{+}$intensity depth profile resulting from a concentration profile for $20<x<10$ is qualitatively in good agreement with the experimental situation (figure 5.b.).

The $\rho_{\mathrm{Fe}}(\mathrm{x})$ function suitable to fit the $\mathrm{Fe}^{+}$intensity spectrum of the sample mixed at $220^{\circ} \mathrm{C}$ at the fluence of $0.8 \times 10^{16} \mathrm{Xe}^{+} / \mathrm{cm}^{2}$ (figure 2.a.) can be found in the same way and is given in figure 6.a..

The $\mathrm{IFe}^{+}$profile (figure 6.b.) qualitatively well reproduce the measurement (figure 2.a.), supposing $0.05<x<0.6$ to fix ideas.

It is here necessary to look for the physical meaning of the fitted exaltation coefficient $\rho_{\mathrm{Fe}}(\mathrm{x})$. The abrupt enhancement of $\rho_{\mathrm{Fe}}(\mathrm{x})$ around $\mathrm{x}=0.16$ is coexisting with the decrease of the exaltation coefficient of $\rho_{\mathrm{Al}}(x)$, since the maxima of $\mathrm{IFe}^{+}$occur at the same sputtering times as the minima of $\mathrm{IAl}^{+}$in the SIMS spectra of the mixed samples (figure 2). So that around $x=0.16$ the ionization probability of Fe atoms is enhanced while the one of $\mathrm{Al}$ atoms is reduced. Such an effect suggests a particular local environment of $\mathrm{Fe}$ and $\mathrm{Al}$ atoms. Therefore it seems reasonnable to attribute the matrix effect to one or several compounds which have been observed by $\mathrm{X}$-ray diffraction.

In $\mathrm{Fe}-\mathrm{Al}$ alloys an electron transfer from $\mathrm{Al}$ to $\mathrm{Fe}$ is revealed by density of states calculations (13 14) in agreement with Pauling electronegativity scale. Such a charge transfer should favour $\mathrm{Al}$ against $\mathrm{Fe}$ ionization, in disagreement with our SIMS spectra. However this picture is certainly far too naïve since it does not take into account for the role of oxygen. Further investigations are necessary to better understand the origin of the matrix effect.

We can deduce that in the multilayer mixed at $370^{\circ} \mathrm{C}$ at the fluence of $1.5 \times 10^{16} \mathrm{Xe}^{+} / \mathrm{cm}^{2}$ the SIMS spectrum reveals the precipitation of a compound with electronic behaviour similar to the one found after mixing at $220^{\circ} \mathrm{C}$.

In conclusion it has been shown that SIMS analysis of composition depth profiles in mixed Fe-Al multilayers reveals the formation of Al-rich compounds inside the initial $\mathrm{Al}$ layers. This point is not questioned even if matrix effects likely exist at low Fe content.

\section{Acknowledgements}

The autors are very grateful to Y. LIMOGE for fruitful comments on the subject discussed in this paper. 


\section{REFERENCES}

(1) Y.T. CHENG, S.J. SIMKO, M.C. MIITELLO, A.A. DOW, G.W. AUNER, M.H. ALKAISI and KR. PADMANABHAN

Nucl. Instr. and Meth. in Phys. Res. B 64 (1992) p. 38.

(2) T.W. WORKMAN, Y.T. CHENG, W.L. JOHNSON, M.A. NICOLET Appl. Phys. Lett., 50 (21) (1987) p. 1485.

(3) Y.T. CHENG, G.W. AUNER, M.M. ALKAISI, K.R. PADMANABHAN, M.M. KARMAKAR Nucl. Inst. and Meth. in Phys. Res., B59/60 (1991) p. 509.

(4) P. BORGESEN, D.A. LILIENFELD, H.H. JOHNSON Appl. Phys. Lett., 57 (14) (1990) p. 1407.

(5) P. BORGESEN, D.A. LILIENFELD, H.H. JOHNSON, T.L. ALFORD, R.E. WISTROM J. Appl. Phys., 68 (3) (1990) p. 1364.

(6) R.J. GABORIAUD, C. JAOUEN, J.J. GROB, A. GROB Appl. Phys. A41 (1986) p. 127.

(7) R.J. GABORIAUD, J.J. GROB, F. ABEL Nucl. Instr. and Meth. in Phys. Res. B 19/20 (1987) p. 648.

(8) M.A. VASCONCELLOS, J.A.T. BORGES da COSTA, W.H. SCHREINER, I.J.R. BAUMVOL Appl. Phys. Lett., 55 (5) (1989) p. 513.

(9) C. DUBOIS, J.C. DUPUY, G. PRUDON, P. PINARD, R. BRENIER, M.F. RAVET, M. PIECUCH, M. MAURER, J.F. BOBO Proceeding of SIMS 8, 15 - 20 Sept. 91, Amsterdam (John WILEY and Sons) 1992.

(10) J.L. SERAN

Thèse d'Etat, Université Paris-Sud, Centre d'Orsay (1979).

(11) B.X. LIU, G.A. CHENG, C.H. SHANG Phil. Mag. Lett., vol. 55 Nº $^{\circ}$ (1987) p. 265.

(12) J.C. PLENET, A. PEREZ, J. RIVORY, O. LABORDE Phys. Rev. B, vol. 47 (1993) p. 3021. 
(13) E. BELIN, Z. DANKHAZI, A. SADOC, Y. CALVAYRAC, T. KLEIN, J.M. DUBOIS J. of Phys. Cond. Matter., 4 (1992) p. 4459.

(14) C.L. FU, M.H. YOO

Mater. Chem. and Phys., 32 (1992) p. 25.

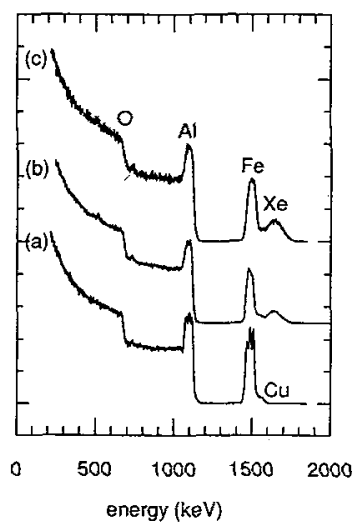

Figure 1: R.B.S. spectra of the Fe-Al samples :

a) as deposited

b) mixed at the fluence of $0.8 \times 10^{16} \mathrm{Xe}^{+} / \mathrm{cm}^{2}$ at $220^{\circ} \mathrm{C}$

c) mixed at the fluence of $1.5 \times 10^{16} \mathrm{Xe}^{+} / \mathrm{cm}^{2}$ at $370^{\circ} \mathrm{C}$ 

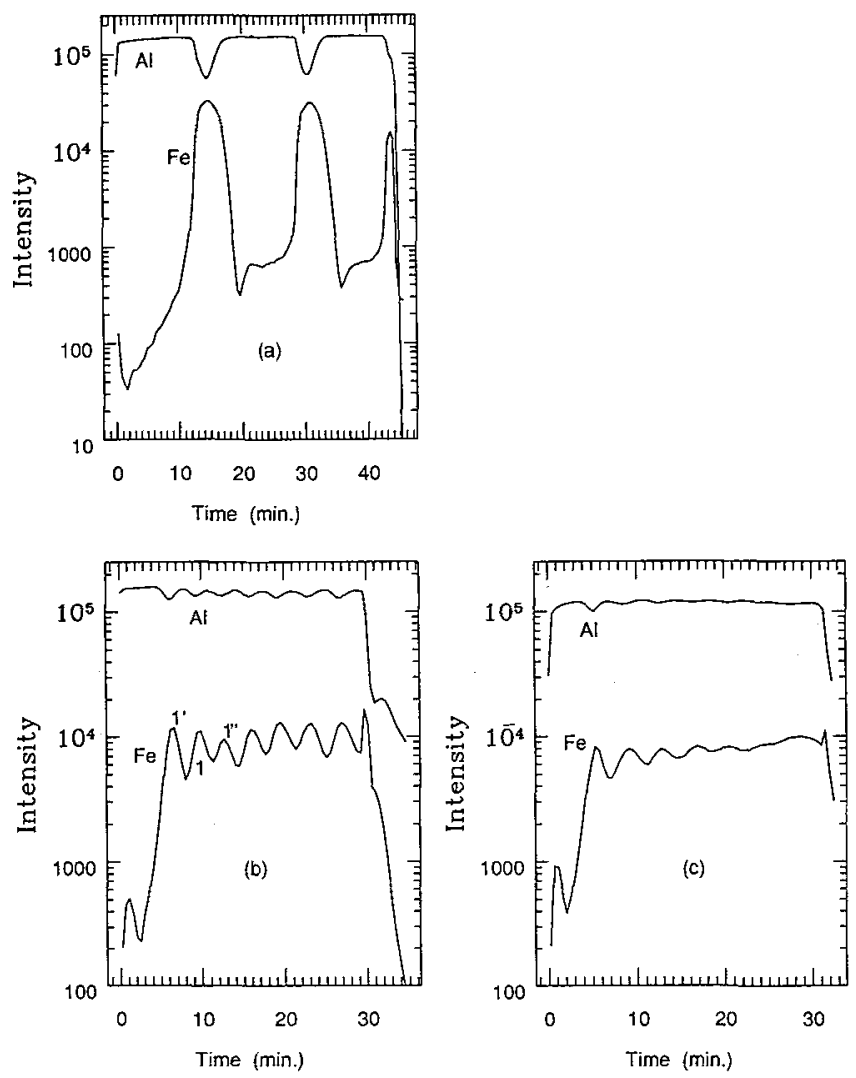

Figure 2 : S.I.M.S. spectra spectra of the Fe-Al samples :

a) as deposited

b) mixed at the fluence of $0.8 \times 10^{16} \mathrm{Xe}^{+} / \mathrm{cm}^{2}$ at $220^{\circ} \mathrm{C}$

c) mixed at the fluence of $1.5 \times 10^{16} \mathrm{Xe}^{+} / \mathrm{cm}^{2}$ at $370^{\circ} \mathrm{C}$

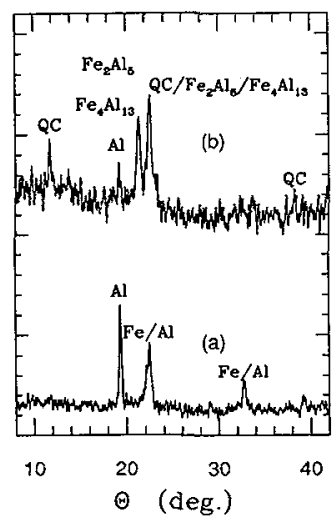

Figure 3: X-ray diffraction patterns at the incidence angle of $0.5^{\circ}$ :

a) as deposited

b) mixed at the fluence of $0.8 \times 10^{16} \mathrm{Xe}^{+} / \mathrm{cm}^{2}$ at $220^{\circ} \mathrm{C}$ 

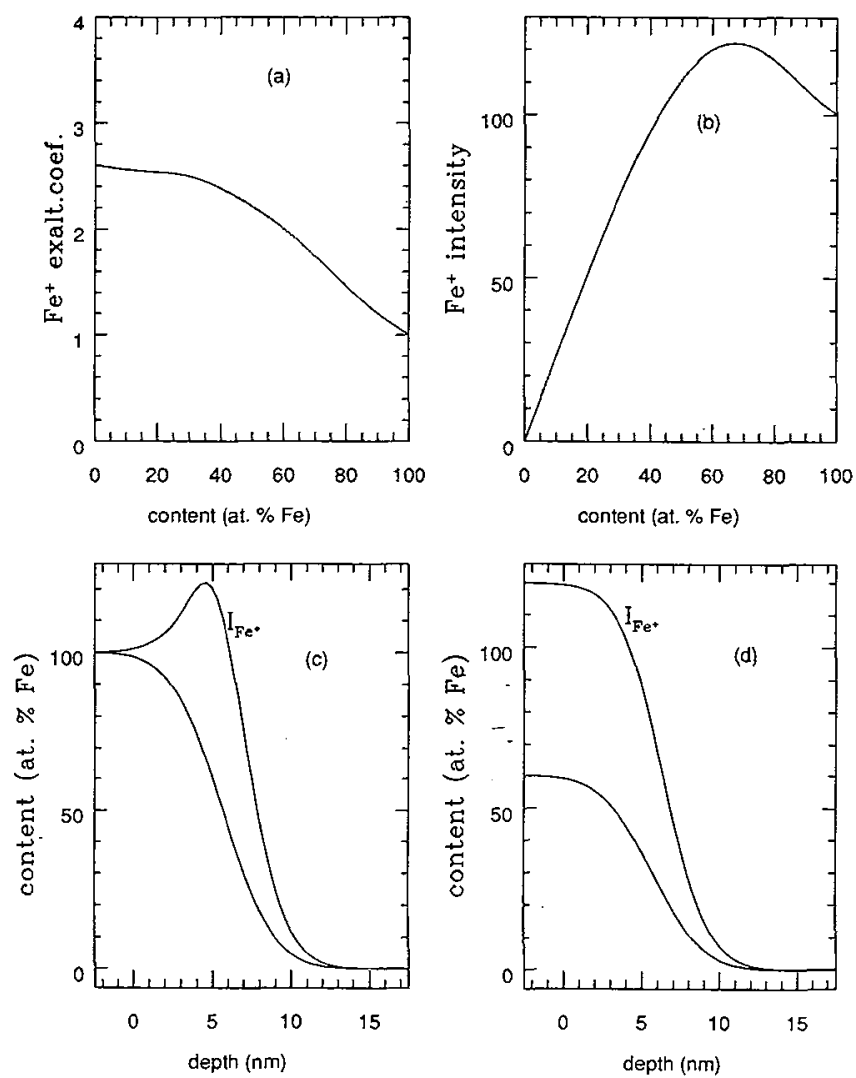

Figure 4 : (a) Exaltation coefficient $\rho_{\mathrm{Fe}}$ following $\mathrm{SERAN}$ (7) in $\mathrm{Fe}_{\mathrm{X}} \mathrm{Al}_{1-\mathrm{X}}$ alloy.

(b) $\mathrm{Fe}^{+}$intensity as a function of $\mathrm{Fe}$ content.

(c) Resulting matrix effect on the analyse of a Fe content profile for $0<x<1$.

(d) Resulting matrix effect on the analyse of a Fe content profile for $0<x<0.6$.
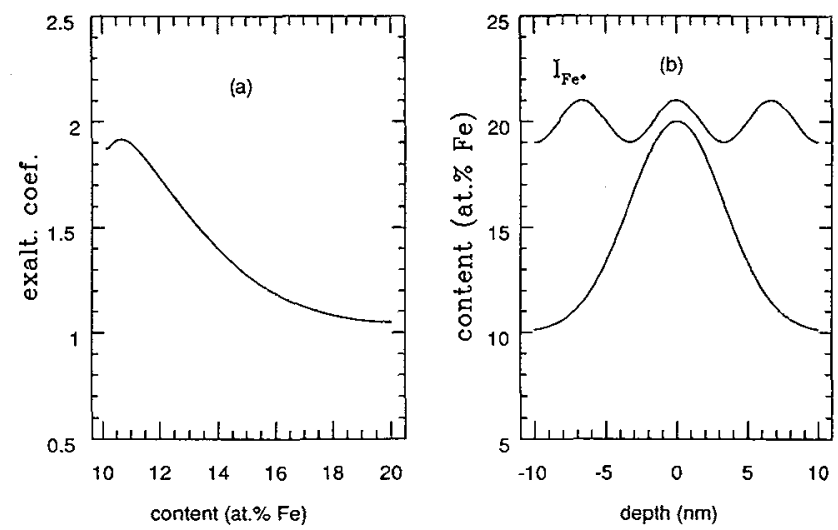

Figure 5 : (a) Exaltation coefficient $\rho_{\mathrm{Fe}}$ necessary to qualitatively reproduce the $\mathrm{IFe}_{\mathrm{Fe}}$ intensity as in the experimental S.I.M.S. spectrum of the sample mixed at $370^{\circ} \mathrm{C}$.

(b) Resulting matrix effect on the analyse of a Fe content profile for $0.1<x<0.2$. 

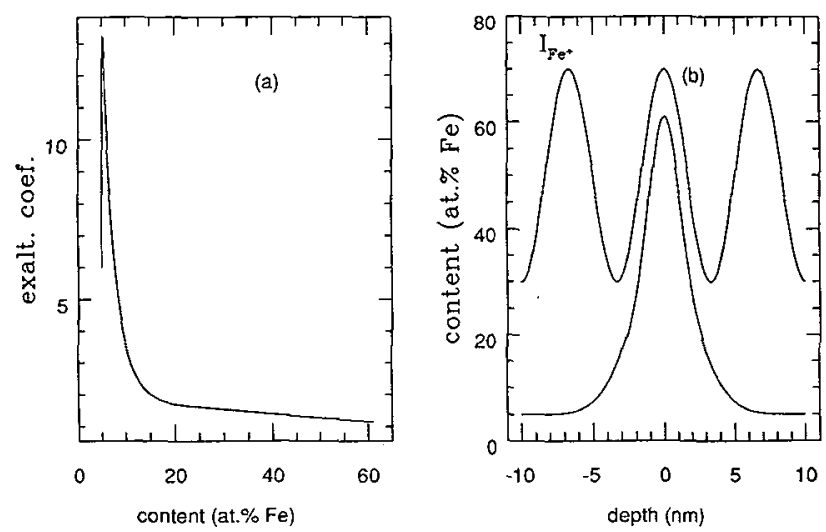

Figure 6: (a) Exaltation coefficient $\rho_{\mathrm{Fe}}$ necessary to qualitatively reproduce the IFe intensity as in the experimental S.I.M.S. spectrum of the sample mixed at $220^{\circ} \mathrm{C}$.

(b) Resulting matrix effect on the analyse of a Fe content profile for $0.05<x<0.6$. 